\title{
World Health Assembly: creating a supportive environment for health
}

Ala Alwan ${ }^{1}$

The World Health Assembly this year was all about creating a supportive and stronger environment for health, both in Member States and in the World Health Organization itself.

The Health Assembly agreed some key reforms for the Organization. The most important for our region was the agreement on a new health emergency programme. This will change the way WHO provides support to countries during outbreaks and emergencies to ensure faster, more efficient and more effective response. It will also provide much needed support for preparedness, strengthening the capacity of first responders in countries and in $\mathrm{WHO}$ country offices. The changes are the result of intensive discussions among and with Member States over the past 18 months and in light of the report of the Review Committee on the Role of the International Health Regulations in the Ebola Outbreak and Response (Ref A/6921). Crucially, the Health Assembly approved an increase in the budget of US\$ 160 million to enable WHO to mobilize the additional resources needed to operationalize the programme. As one of the regions most heavily affected by emergencies, and at risk of disease outbreaks as a result, our region will be a substantial beneficiary of this new programme. Moreover, we have already started to implement a key component of the programme, which is the Joint External Evaluation of countries' core capacities under the International Health Regulations (2005).

The Health Assembly also approved a number of significant reforms in the governance of $\mathrm{WHO}$, contributing to the ongoing process of making $\mathrm{WHO}$ more effective, efficient, transparent and accountable. They included a landmark agreement, following several years of negotiations, on a framework of engagement with non-State actors. This will enable WHO to work with a broader range of entities in an innovative and productive manner that will benefit public health as a whole. They also included recommendations aimed at streamlining the increasingly crowded agenda of the Health Assembly itself, to ensure that it aligns with the strategic priorities set and can be managed efficiently, and that subsequent decisions can be implemented by Member States.

The 2030 agenda for sustainable development was the constant theme of the Health Assembly. The agenda was agreed by the United Nations in September 2015 in the form of 17 Sustainable Development Goals (SDGs) to succeed the Millennium Development Goals (MDGs). These are acknowledged to be broader in scope than the MDGs and to be relevant to all countries, covering the economic, environmental and social pillars of sustainable development with a strong focus on equity to ensure that 'no one will be left behind' ${ }^{\prime}$. Delegates to the Health Assembly reiterated this core principle of the SDGs in the plenary and the discussions around many of the agenda items, as WHO seeks to align existing global health strategies and targets with those set for SDG 3, specifically, and for

United Nations General Assembly resolution $1 / 70$, paragraph 4 . other SDGs that relate closely to and impact on WHO's work.

Universal health coverage, in particular, with its emphasis on equitable access to quality health services, will be key to achieving health-related targets. As Director-General Margaret Chan said in her opening address, "Universal health coverage is the target that underpins all others. It is the ultimate expression of fairness that leaves no one behind." The Health Assembly endorsed two important resolutions of direct relevance to enhancing the environment for health in this regard. In a resolution on strengthening essential public health functions in support of the achievement of universal health coverage, it called on Member States to show leadership and ownership in establishing effective health governance by national and subnational authorities. This resolution is very timely for our region, where, in the past two years, we have established an initiative aimed at supporting countries to assess their essential public health functions with a view to identifying shortcomings and overcoming them. It also endorsed a resolution on a global strategy on human resources for health aimed at addressing the global health workforce deficit. This is already being translated into a framework for action in our region.

A concurrent and related theme to sustainable development was that of climate change. The scene was set by Christiana Figueres, Executive Secretary of the United Nations Framework Convention on Climate Change, guest speaker to the World Health Assembly. She emphasized the importance for 
health protection of the 2015 Paris agreement on climate change. Furthermore, she drew attention to the key role that the health community has played, and continues to play, in supporting action on climate change. Above all, she highlighted the inseparability of action on climate change from the agenda for sustainable development. Later on in the week, the Health Assembly endorsed key resolutions on a road map for an enhanced global response to the adverse health effects of air pollution and on the role of the health sector in the sound management of chemicals, both of which can have a profound impact in the context of climate change.
The 69th World Health Assembly was one of the most intense of recent years. The packed agenda addressed many more issues, and delegates agreed on important strategic actions in numerous areas ${ }^{2}$ aimed at improving access to and quality of health care for women, children, adolescents, migrants, older people, and people living with HIV, viral hepatitis and sexually transmitted diseases among others. They agreed on actions to end inappropriate promotion of foods for infants and young children. They also agreed on a global action plan on

2 http://apps.who.int/gb/e/e_wha69. antimicrobial resistance, one of the most challenging problems today, and they agreed to add mycetoma, a debilitating disease that affects poor people in the Eastern Mediterranean, African and other regions, to the list of neglected tropical diseases, a move that will enable the mobilization of greatly needed funds for action.

Each year, the Health Assembly proves yet again that it is an opportunity for governments around the world to come together to discuss and reach consensus on key challenges in global health and health development in Member States and a continued source of hope in difficult times. 